\title{
Understanding the Innovation Ecosystem in Mining and What the Digital Revolution Means for It
}

John Steen, Sam Macaulay, Nadja Kunz, and John Jackson

\section{CONTENTS}

1.1 Introduction

1.2 Does Innovation Happen Differently in the Mining Sector? .................. 5

1.3 Mining Companies as Process Innovators and Consumers of Innovation 8

1.4 Complexity and Silos as Barriers to Innovation in Mining................... 13

1.5 Managing Mine Innovation in a Digital Environment:

Lessons from Other Industries ........................................................... 14

1.5.1 Lessons from Digital Technology in Agriculture:

Supply Chain and Value Chain Coordination............................ 16

1.5.2 Lessons from Digital Technology in Aerospace:

New Management Capabilities and Network Governance....... 18

1.6 The Digitization of Architectural Knowledge and the Impending

Competition for its Control ................................................................20

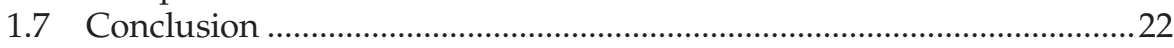

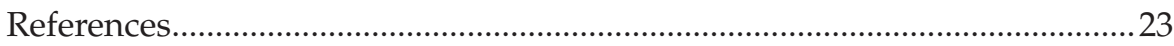

\subsection{Introduction}

One thing that is clear about economic development is that sustainable improvements in productivity come from technical change (Eslake and Walsh 2011). During the period of inflated commodity prices leading up to 2013, profitability in mining was high but productivity declined as mining companies rapidly expanded their operations. With a focus on production rather than efficiency, mining companies opened high-cost mines to meet demand (Eslake and Walsh 2011; Syed 2013). 
Since the sustained decline in prices over the past years, productivity has returned to center stage as a concern for mine managers. Between 2013 and 2015, surveys of executives showed that productivity declines were identified as a key risk for the industry and cost reduction was prioritized (Mitchell and Steen 2014; Mitchell et al. 2017). Although the initial focus was on labor cost reduction and squeezing input prices, mining companies renewed an interest in innovation to address long-term challenges that could not be met by short-term cost cutting. Several reports noted that in the long term, mining productivity will decline due to exhaustion of highquality resource deposits in easy-to-access locations (Syed 2013). Critical inputs for mines such as energy and water also will become more expensive. Increased scrutiny by community and governments also will challenge the social license to operate. Consequently, mining companies must find ways to minimize environmental impacts and show benefits to the regions in which they operate. This focus also will require the mining industry to innovate.

The mining industry has a long history of innovation. One study of copper mining shows the step change reductions in operating costs that come with successive introduction of new technology over the past century (Tilton and Landsberg 1997). Although the economies of scale that come with industry expansion can account for $30 \%$ of cost reduction, innovations such as solvent extraction electrowinning (SXEW; hydrometallurgical processing rather than smelting) and computerization of operations can account for $70 \%$ of the cost reduction during that time.

However, the pressure to improve the innovation performance of the mining industry to address these long-term challenges means that mining companies need to fundamentally change the way they innovate. We agree with recent commentary by the Rio Tinto Group that innovation in mining is different from other industries (Shook 2015), but we also suggest that important similarities with other industries provide examples of how mining companies can embrace a more innovative future. Furthermore, digital technology will be a key enabler of innovation in the mining industry and will have profound effects on the nature of competitive advantage in the mining industry sector and the relationship between mining companies and their technology suppliers.

Characterizing the nature of innovation in the mining industry sector is important because most mining innovation takes the form of process innovation and on-site problem solving, which is not well captured by traditional innovation measures such as research and development (R\&D) expenditure and patents (Kastelle and Steen 2011). Mining companies are also net-consumers of innovation and rely heavily on the mining equipment, technology, and services (METS) sector for solutions and new technology. Understanding this relationship between mining companies and their supply chains is crucial for making sense of innovation in mining as a 
special case of open innovation (Dodgson and Steen 2008). A third feature of innovation in mining is that mines are systems of connected technologies known as complex capital goods (Acha et al. 2004). This last point has two implications for mine innovation in that innovation can be hidden within these complex capital goods and not readily measured in surveys of mining innovation. The other implication is that new technology enters a mine as part of a deeply interdependent social, technical, and organizational system and this implication makes the introduction of innovation especially challenging in the mining industry sector.

Although mining does have obstacles to innovation, other industries also share these attributes of being innovation consumers and innovating in complex production systems. Mining executives are currently interested in digital technology for improving efficiency through cost reduction, but we can draw on experiences in adjacent industries to argue that digital technology also can be used to facilitate the introduction of more radical innovations in complex business environments.

We discuss how digital technology within the innovation process might allow mining companies to innovate in areas that will become critical in the future such as better use of water and managing the mine through the entire lifecycle from planning to decommissioning. Throughout the discussion, we illustrate key points with quotes from interviews that were conducted between 2014 and 2016 with mining managers and executives from Australia, North America, Africa, and South America as part of exploratory research into innovation and productivity in the mining industry. We conducted all these interviews with ethical research approval from the University of Queensland and recorded them with the permission of the interviewees for analysis.

\subsection{Does Innovation Happen Differently in the Mining Sector?}

The mining industry has a reputation for being reluctant to innovate (Hanson et al. 1997; Dodgson and Steen 2008; Mitchell et al. 2014). This reputation is not solely based on the views of outsiders. Rather, it is often heard from those in the industry. For example, the Anglo American plc chief executive officer (CEO), Mark Cutifani, declared that unless mining companies improve their innovation performance they will become subsidiaries of proven innovators like General Electric (GE) Mining (Mitchell et al. 2014). Several industry reports have commented on the low rate of R\&D spending in mining, especially in comparison to similar industries such as oil and gas (Mitchell and Steen 2014). In our interview series we generally found that interviewees agreed that mining was not a very innovative industry and this lack was attributed to a range of factors. Some interviewees pointed to a general 
problem of a business culture that avoided innovation and preferred to use established technology and procedures:

...you can see the productivity gain would be enormous and the technical challenge is not difficult at all. But it's more of a cultural thing within the mining space; there seems to be a bit of push back on innovating and finding a new way of doing things. (Australian GM)

Several interviewees mentioned the short-term time horizon often applied to innovation investments. The underlying reason for this short-term horizon, though not clear, may be associated with the volatile nature of cash flows and profits that are most driven by commodity prices.

...gosh, how many times have I seen let's use the word innovation or something; people trying to launch initiatives, be it at the asset level or even at the group level. But the moment anything like innovation comes along, and anything that could be bucketed under innovation, it has a very short shelf life in the mining culture. (North American CFO)

In one of my predecessor companies, our leaders set up a technology group and they were working on things like "Let's trans-levitate rock out of the pit using linear synchronous motors." And I am sorry, you can work on that for 10 years and you are not going to deliver any value. So, I am sorry to be this way, but this pie in the sky, "we are going to reinvent the world," I am not a big fan of that. (North American CEO)

Through necessity, we kind of moved into "We need to generate value, and we need to generate value on a very short time horizon." So that sort of eliminates anything too clever and too thoughtful. (UK GM)

One way of thinking about this short-term focus is that mining companies have a limited appetite for business risk. In one discussion, an Australian mine manager explained that mining companies had a finite budget for risk and most of this was allocated to exploration and development. When innovation does happen, it tends to be in response to persistent challenges that threaten the business, such as sustained periods of low margins or logistics for a remote operation. Mining businesses tend to innovate when they must do so.

...many years ago we had to work with a lot of smaller margins in terms of operating a gold mine or a copper mine or a silver mine. So, we were a little more entrepreneurial and innovative about some of the things that we did. I think the last decade of high metal prices is taking some of that out of us. (North American CFO)

Yeah, so, I think the mining industry is pretty good at R\&D and innovation. Some of that actually would come out of necessity: if you're working in remote parts of the world you need to be able to somehow make the mine more independent. (North American R\&D director)

This conservatism also means that the preferred approach to innovation is to be a fast follower rather than the leader who wears the cost of developing the technology and solving the problems associated with it. 
I think you have always got to be open-minded over technology. And particularly you have always got to be looking for disruptive technology and that doesn't mean you need to be the proving ground; you just need to be a fast follower and so if Rio Tinto wants to go and manage automated trucks and stuff like that, okay we will watch them closely, but will be prepared to implement that when they get it right. (Australian COO)

In addition to the broad explanation of culture, some interviewees offered more specific reasons for why mining companies were reluctant to be radical innovators. One of these reasons was due to the nature of competition. As long as the big mining companies compete on ownership of long-life, low-cost deposits, technology only needs to be fit for purpose rather than source of competitive advantage. In other words, mining companies only innovate when they are forced to.

The definition of a world class resource is one that survives five generations of incompetent management. You end up with these big behemoth mining companies sitting on great geological resources, and it sort of crowds out the ability for innovative companies to come in and shake things about. (South American GM).

Beyond the nature of competition, the way that mining companies have been traditionally structured as portfolios of relatively independent mines also limits innovation to small-scale programs that fit the budget cycle of a mine manager (Mitchell et al. 2017). Radical innovation needs longer time frames and greater financial returns that can be achieved from implementing new processes across the business to achieve higher returns on investment.

If you want to introduce disruptive innovation in mining, you cannot do it with the level of autonomy and empowerment that is currently given to site manager. There has to be some recentralization of the technology to make a major change. (North American R\&D director).

Paradoxically, some executives identify the problem of justifying innovation in a large-scale operation with high operating costs unless the return was of a magnitude that was similar to the scale of the costs and profit. While pointing to the need for innovation to generate immediate returns at low risk, these returns also had to be sufficiently large to justify attention from senior managers. This is a paradox because high returns on investment must involve taking bigger risks. Clearly this mindset of wanting big rewards with minimal risk is going to be a barrier to any systematic innovation program due to the incompatibility of high returns and low risk.

If you get a lot of automation into your mine, and the trucks, and the data, and - you will see the massive benefits, but counterfactual to that, as you say, there's actually a fairly massive cost, and if all you are doing 
is realizing 10 percent on your cost, then it's pretty hard to justify that economically, and you know, if you are making 40 dollars a ton it's not shifting the dial, you know, for the amount of risk you're taking on. (South American Mining Executive).

While coming up with reasons for the mining industry's reputation for slow and incremental innovation, several respondents questioned how sustainable this lethargic pace of innovation was in the long term. The mining industry executives understand the importance of innovation but when it comes to committing resources to make it happen, mining companies have little resolve to move forward.

....but it is clear to me that we have got to ask the question, are there more incremental solutions available, or is it time to do something more radical? (African Chairman).

You get to a point where, without some sort of innovation or something like that, you would get to a point where you are just going to get diminishing returns on the effort you are trying to put into improve it. (Australian GM).

The evidence from these interviews reinforces the view that innovation in mining has become slow and incremental, especially in recent years. However, finding quantitative answers to the question of what type of innovation do mining companies do and how much innovation happens in the mining industry is difficult due to the lack of fine-grained data on the mining industry sector. Innovation surveys based on the European Union Community Innovation Survey have been around in many countries since the 1970s, but these cover a cross section of national economies and do not capture sufficient data from the mining industry sector to address the question of what mining innovation looks like (Dodgson and Steen 2008). Answering this question is important because different industries have different innovation signatures and comparing dissimilar industries may lead to erroneous conclusions about the future of mining and how it might be shaped by innovation.

\subsection{Mining Companies as Process Innovators and Consumers of Innovation}

If innovation does have different characteristics in the mining industry compared to other parts of the economy, then what might some of these differences look like? In considering this question it is useful to think about classifications of various forms of innovation. One of the founders of innovation economics, Schumpeter (1912), took a broad view of innovation that 
could include new products and services, new production processes, new markets, and new sources of supply, as well as changing the structure of the industry.

Discussing these different forms of innovation is important because in our interviews we encountered many differing interpretations of what constitutes innovation in mining. This variation often extends to differences in the same mine site. While one manager will explain that no innovation happens on site, another manager will give details on several innovations that were introduced to key production activities. This disconnect is not because the innovation is secret but rather because there is not a common language for innovation in mining.

Most mining companies tend not to produce new products although there are some exceptions in vertically integrated businesses that transform commodities into value-added products. It is also possible to argue that blending sources of commodities from different mines to meet customer needs, such as iron ore in the Pilbara region of Australia, is a form of product innovation. Most commonly, innovation in mining takes the form of improved processes. Although many of our interviewees do not call it innovation, it is apparent that process innovation is very important to the mining industry. Some examples from our interviews include improving efficiency in asset utilization and management:

In the future there are huge improvements that people are looking at in terms of the planning and scheduling of fleets, the planning and scheduling of fleet maintenance as well, those sorts of things. (North American CEO)

Other examples of process integration included better connections between the steps in the ore processing pathway.

...they improved the output from 13 million ton to 14.5 million, you know, that's 1.5 million ton over 13, but with the same fleet, with the same volume mined, but much improved. And it was a huge joint effort. It involved right from the mineral resource management in terms of knowing and predicting what you are going to mine and blast, all the way to analyzing the losses and everything in the processing system. (African Director)

Although these are certainly process innovations, measurement of them and quantifying their impact on the business is a challenge for researchers and mine managers. Although new product development can be isolated from business activities, process innovations tend to be done on site within the business and are harder to analytically separate from non-innovative activities. As highlighted in the previous quote, process innovation can have a huge impact but also tends to be an accumulation of smaller innovations over time. Consequently, this accumulation of small process innovations can 
be invisible to senior executives and sometimes an early target in a round of budget cutting.

The other signature of innovation in the mining industry is that mining companies are predominantly consumers of innovation produced by the METS sector. Measuring patents shows that the METS sector produces vastly more innovation processes than the mining companies and that this gap between them is growing (Figure 1.1).

The innovativeness of the METS sector comes with diversity as providers compete across different technologies and customers. In a study done for the

AQ 4 Minerals Council of Australia, Scott-Kemmis (2013) mapped the interrelationships between different subsectors of the METS sector (Figure 2.2). This map represents a wide array of products and services with some services such as consulting and design and project management playing a connecting role between other specializations. This map shows a diverse and connected industrial ecosystem within the mining supply chain that accounts for much of its innovativeness relative to the mining companies.

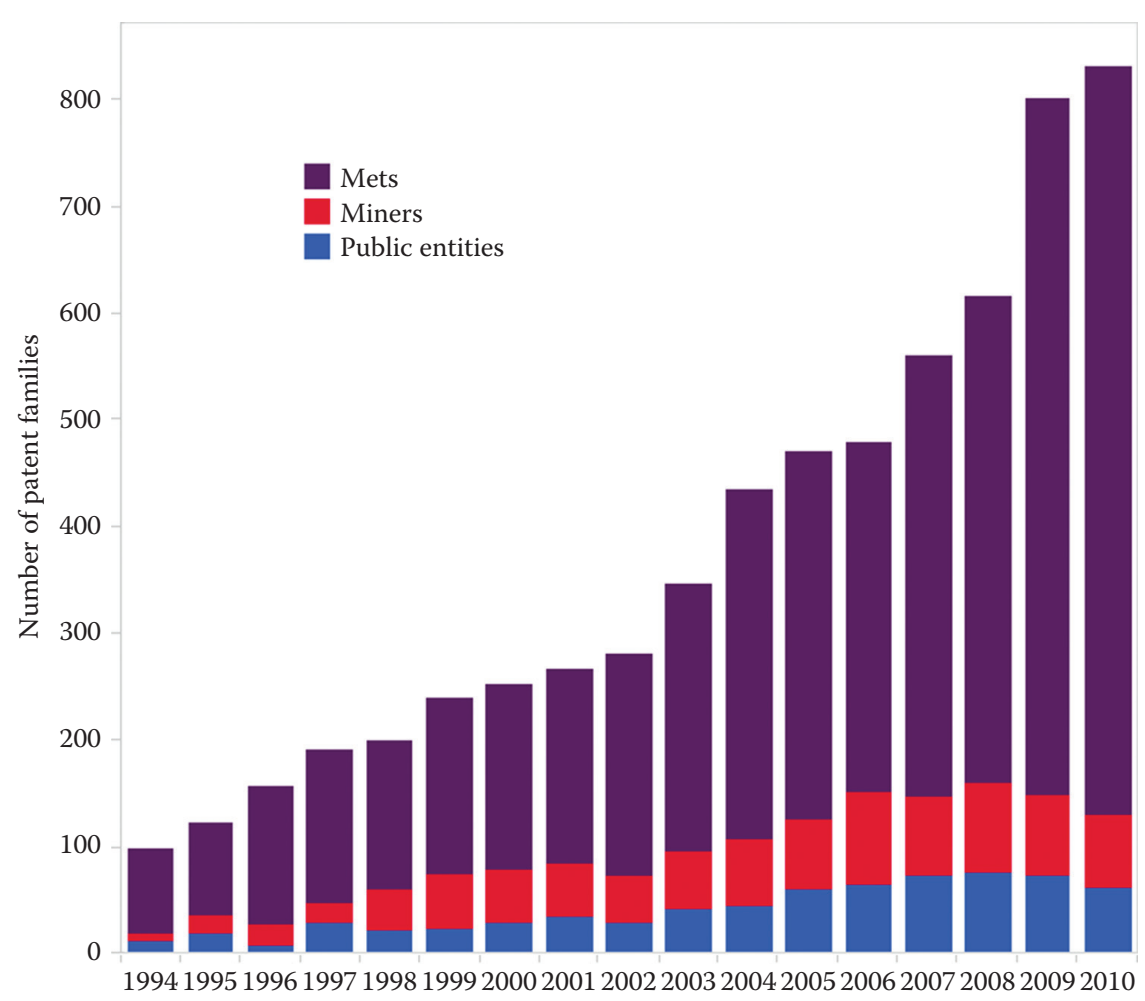

FIGURE 1.1

Ownership of patent families by mining companies versus METS sector and other public research providers (Francis 2015; Australian data). 


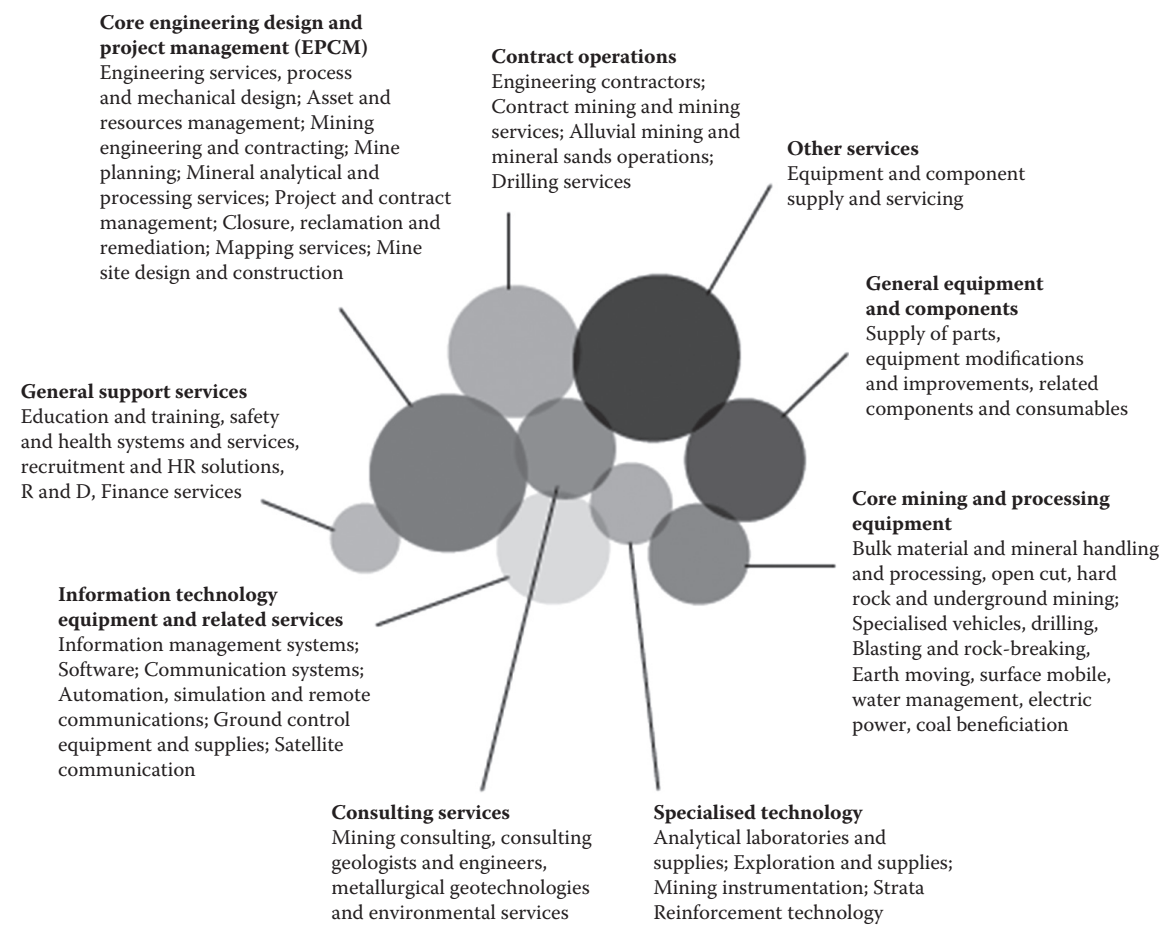

FIGURE 1.2

Relationships between subsectors of the METSsector (Scott-Kemmis 2013).

In this diagram (Figure 2.2) from 2013, the category "Information technology and related services" is one of the smaller categories of subsectors on the periphery of the cluster. However, this is deceptive because we know that this sector has not only become bigger but is also embedded in the technology and capabilities of all the other service sectors (Francis 2015). With the blurring of technological boundaries, it becomes harder to define the technological boundaries of METS sector because a range of new information technology (IT) service companies such as SAP, IBM, and GE Digital have become part of the mining supply chain.

If the METS sector is providing innovation for mining, then how can mining companies make more of this innovative capacity? At least two considerations suggest how mining companies can create a more innovative industrial ecosystem. The first of these considerations is the principle of absorptive capacity (Cohen and Levinthal 1990) which states that organizations are unable to absorb innovation unless they are capable of producing innovations and implementing them within the business. The second of these considerations is collaborative supply chain relationships with innovation incentives and risk sharing/risk bearing agreements (Caldwell 2009; Steen et al. 2017). 
Traditionally, mining companies have transactional relationships with the supply chain where procurement managers endeavor to find technology and capabilities at the lowest price and structure the contract to transfer delivery risk to the supplier. In other industries, such as construction, this approach has been shown to stifle innovation because the supplier will do just enough to fulfil the requirements of the contract. With no incentive for finding a better solution, the introduction of a new process by the contractor simply becomes risky and financially unviable for them (Davies et al. 2014).

Typically, digital technology is considered as an outcome of innovation but there are many examples of digital technology being a catalyst for innovation, especially in the areas of improving absorptive capacity and facilitating collaboration between businesses. Dodgson et al. (2005) coined the term "innovation technologies" which span a range of forms and applications including data mining, 3D printing, computer-aided design (CAD), computer simulation, and virtual collaboration (Salter et al. 2005). Innovation technologies improve innovation performance in settings such as car manufacturing, architecture, and services such as hospitals and also may be especially important in large, complex, capital intensive businesses like mining.

Prototyping and experimentation are important for innovation which might be easy for small consumer products but how can we experiment in a mine without risking safety and production? Simulation and visualization can enable performance of experiments in virtual mines without the risk of performing real experiments. Mine simulation technology already exists to assist with optimizing scheduling of mine development and load and haul decisions, so Dodgson et al. (2007) have shown how simulation can gather important information about the cascading effects of new technology in complex technological systems and can foster collaboration within the organization and with external stakeholders. Visualization allows these stakeholders to see the results of the new technology and offer their input into the design process (Gann and Dodgson 2008).

The internet has become the basis for many forms of innovation technology, especially for opening up a business' unsolved problems and intellectual property base. Proctor and Gamble developed an internet portal to find external partners to commercialize their unused intellectual property (Dodgson et al. 2006) and Goldcorp famously developed their Red Lake mine in 2000 by posting geological data on the internet and offering a prize for the best model of the resource (Saefong 2016).

Innovation technologies also can change the relationship between businesses and their supply chains by encouraging more collaboration and risk sharing. Forsythe et al. (2015) studied the effects of construction simulation technology (building information modeling [BIM]) on the relationship between builders and their suppliers. They found that BIM enabled the sharing of information so that contracts were more easily managed, and a higher level of collaboration could exist between project owners and contractors. 
However, innovation technologies alone will not make mining companies more innovative. The way that mines and mining companies are organized also will need to change to become better integrated

\subsection{Complexity and Silos as Barriers to Innovation in Mining}

One barrier to increased process integration in mining may be explained by the hierarchical structure that is characteristic of most major mining companies. Mine sites are typically structured following the Mintzberg (1981) Machine Bureaucracy (i.e., a large operating core conducting lowskilled and specialized work supported by a large middle management and a small upper management). This structure is effective for optimizing individual system components (e.g., mining, processing, environment, and community relations). However, this structure creates challenges for optimization across the value chain. Many mines suffer from communication "silos" across departmental functions (Kemp and Owen 2013; Kunz et al. 2017) such that individuals are so specialized that they can no longer see the big picture.

I made a comment to a manager who was running a coal plant for me when I was running the mine there and I said, "Your job is to optimize the coal plant..." and I was responsible for the coal plant, the tech services, the mine and the likes... and my job is not to let you. My job is to optimize across all of them but with the tools you've got you're supposed to try and optimize what you've got there." (UK GM)

Engineering efforts to overcome this integration challenge are widespread. For example, concepts such as "mine-to-mill" and the more recent "cave-to-mill" have highlighted the importance of optimizing net present value (NPV) from ore extraction through to the processing circuit (Nadolski et al. 2015). Recently, scholars have also encouraged mining companies to adopt an integrated approach to designing mining tailings in a way that anticipates and prevents environmental legacies that have historically arisen at mine closure (Edraki et al. 2014).

The integration challenge will become ever-more critical for mining companies in the future. Technical complexity is set to increase due to declining ore grades, more complex mineralogy, and deeper deposits which will broaden the environmental footprint of mines. Mining companies will need new technological innovations and mass-mining methods to extract ore from more remote locations. The increased social conflicts associated across the mining industry sector also will exert growing pressure on mining companies to minimize their environmental impacts (Hodge 2014). This effort will 
create a challenge because complex socio-technical systems are inherently challenging to optimize and control as stated by <add interviewee >:

This will create a challenge because complex socio-technical systems are inherently challenging to optimize and control:

\begin{abstract}
...if you want to rely on human heuristics to do this integrated value optimisation, then you can only do that within relatively limited size of teams. Once you get above a thousand people in a team then it becomes very difficult to get that connectivity.
\end{abstract}

The "Machine Bureaucracy" may have been an effective structure for the mining industry of the past when it operated in traditional command-andcontrol paradigms; however, its rigidity impedes adaptability and resilience. A further challenge is disconnects in vertical integration from the CEO to operator (Kunz 2016). Systems optimization is therefore also reliant on middle management to connect tactics and strategy. Unfortunately, research reveals that many mining companies have a lack of strategic thinkers at these levels. As reported in Mitchell et al. (2014), several of the CEOs who we interviewed observed that most system thinkers in the mining industry sector are at such a senior level that they are side-lined from the day-to-day operations of the mine. Kunz (2013) coined this problem as the "missing middle" and found that it could have significant implications for managing water on mines, an example of an issue that requires a systems approach.

Addressing the mine integration problem therefore requires not only technical innovation but also innovations in the human systems responsible for management. Incentive structures including key performance indicators (KPIs) may need a rethink as they may be impeding innovation. These incentive structures must be linked to systemic goals, not only to task functions. As we were told by one R\&D executive:

I said before that there is not going to be real innovation in mining for as long as engineers are paid by the hour, because the whole model, the supply chain procurement model that pulls together the mining system is not able to embrace technology risk effectively, in a controlled manner (North American R\&D director).

\title{
1.5 Managing Mine Innovation in a Digital Environment: Lessons from Other Industries
}

The fundamental enabler of digital technology is the exponentially increasing processing power of computer chips which at the same time are becoming smaller and cheaper. What this means is that data can be generated, processed, and integrated in a way that was not previously possible. This is the 
age of the "Internet of things" where people and machines are connected through the constant collection and transmission of data.

The digitization of mining is not the normal incremental or radical type of innovation that mining firms are used to dealing with. Instead, digitization represents a systemic architectural innovation (Henderson and Clark 1990) that changes the way in which the components of a mining system are linked together. This type of innovation is recognized as being difficult to respond to and manage because, although it changes the way components are linked together, it leaves the identity and knowledge of individual components relatively untouched and can thus be hard to recognize until it is too late to adapt. In our interviews, several executives commented on the problem of getting value from data. Mines can generate a huge quantity of information but verifying the quality of the data and connecting it to processes and better decisions is a problem according to many mining executives. The following quote typical of many similar comments:

We collect ten times more data than we even look at. So why collect it? Because we thought it was valuable to do so. But yet we do not look at it. So, let's start looking at the data we already collect. (Australian Operations Manager)

Digital technology is an enabler of a new integrated business architecture and the linking of different systems within a mine to dynamically optimize production but this transformation is not straightforward.

Building the model sounds so simple, but I've seldom come across it ever actually, a fully integrated model that goes right across the mine value chain from one end to the other that doesn't have other feed ins from spreadsheets and all sorts of other things along the way - that fully integrated model that's actually picking up information independently from the processes and running real time is still something that seems to be very, very difficult to put together (South African Director)

However, the technology alone will not produce this integration across the mine functions. Without changes to the organization in terms of decision responsibilities, roles, and information flow, the digital revolution in mining has so far been disappointing.

Things like SAP are a business tool and, by themselves, add zero value. It is the processes you put around them that may or may not add value. In the way it was done in the organizations that I have worked in, they were a complete disaster, in my opinion. Value destructive, in my opinion. (Australian Director)

Digitization is fundamentally transforming the knowledge required to construct, maintain, and orchestrate linkages within big mining businesses 
and within the supply chain. Those that control this knowledge are likely to dominate the future of mining. One interviewee, a North American R\&D director, used the example of aircraft manufacturing to show how dominant businesses were active curators of an innovative industrial network.

\begin{abstract}
You can look at integration as an internal system problem. But then to reap the real benefits you need to look at external integration, and that means risk allocation across the equipment supply chain. Let's look at an aircraft manufacturer putting together a new model of aircraft, a new aircraft product. They do not generally go out with a prospectus to raise $\$ 5$ billion to create this new aircraft, it is just routine business, and a lot of their suppliers pay to participate in consortia or in commercial teams that share the development risk. (North American R\&D director)
\end{abstract}

To understand the potential trajectory of digital technology in mining and how it might influence innovation, we turn to two exemplar industries that share some similarities with the mining industry. From these cases we draw some conclusions on how digital technology might change the mining innovation ecosystem.

\title{
1.5.1 Lessons from Digital Technology in Agriculture: Supply Chain and Value Chain Coordination
}

The agricultural industry has many parallels to the mining industry: being exposed to cyclical commodity prices, the variability of the inputs to downstream processing, complex four-dimensional (space and time) production systems, production cost pressures with a drive to produce yield and quality, and historically slow rates of adoption of innovation. Some sectors of the agricultural industry, particularly broad acre crops and viticulture have been undergoing a digital transformation since the 1980s, commencing with precision agriculture and evolving in recent times to big data. Productivity gains of between 5\% and 35\% have been reported for various crops with half coming from input efficiencies and half from increases in rates of production output (Watcharaanantapong et al. 2014; Keogh and Henry 2016; Castle et al. 2016). These gains are similar to those suggested to be possible by the mining industry, with digitization enabling improved integration through architectural innovation (McKee 2016; Mitchell et al. 2017).

Precision agriculture can be defined as the application of information technologies to improve the management of inputs, the quantity and quality of outputs, and profitability by enabling the right management strategy at the right place at the right time (Pierce and Nowak 1999; Sonka 2016). This precision agriculture is achieved by measuring key characteristics of the soil, crop quality, and quantity at high spatial-temporal resolutions across the lifecycle of production including pre-sowing, sowing, in-crop, and harvesting. The analogous approach in the mining industry would be measuring key 
characteristics of the mineral deposit such as mineralogy, texture, hardness, potential acid generation, acid consumption, and size distributions in addition to the standard measures of grades (elemental content) at improved resolutions, coupled with integrated planning across planning, production, and disposal. Such an approach is currently rare due to the lack of sensors that can measure these inputs and the inability to analyse processes in real time with true integrated planning systems.

Studies of new technology and innovation within the agricultural sector indicate that usefulness and ease of use are important for adoption but with the caveat that there is not a significant increase in production cost, irrespective of improvements in revenue (Castle et al. 2016; Pierpaoli et al. 2013). An additional factor is the perception of the risk in adopting the new technologies (Marra et al. 2003). The perception is based on several factors including a producer's existing practices and the uncertainty surrounding the cost savings that will be achieved. A study of corn producers in the United States found that the advanced precision agricultural systems resulted in variable cost savings relative to the intermediate systems, although in some cases, the advanced systems can lead to increased outputs and profits (Schimmelpfenning and Ebel 2016). This variability in outcomes is typical for the application of new technology in complex production systems. Exacerbating the situation is that for both the agricultural and mining industry, significant difficulties exist in estimating the financial benefits associated with the adoption of digital innovation due to the predominance of static and conservative financial modelling tools such as discounted cash flow analysis which does not easily accommodate estimations of the value of innovation investments (Hayward et al. 2017).

Although it can be argued that big data has been used in precision agriculture for many years, it is enhancing the ability to enabling learning, prediction, and optimization of farm production not only at individual farm scale but also at district and regional level such as the American Midwest (Sonka 2016; Wolfert et al. 2017). Open data platforms have been embraced in the United States which has resulted in ease of data transfer between businesses and software platforms. This result also led to new applications and services in data storage and management. However, big data can only reliably deliver long-term business advantage when fully integrated with traditional data management and governance processes (Wolfert 2017). The focus to date within the mining industry is primarily at the mine site level but a gradual move to open data standards has gathered momentum over the past few years through bodies such as the Global Mining and Standards Guidelines Group (GMSG 2017).

The consensus in agriculture is that it will take 5-7 years from the acquisition of relevant data (e.g., soil data, yield, weather, and other inputs) to demonstrate clear observable improvements in outcomes for the industry. This consensus reflects the time required to acquire data from sufficient seasons and develop useful and robust models, algorithms, and analytics. 
Thus, the payback from the initial investment in digital technology is relatively long term and without adequate capital can be a barrier to adoption. A similar time frame is likely for the mining industry across the integrated value chain but with some improvements likely in the short term for specific functions such as asset management and fleet maintenance.

The industrial networks in agribusiness exhibit a high degree of dynamism with new players entering the industry and the incumbents assuming different roles. New relationships have been formed among competing and collaborating firms, suppliers and customers, and stakeholders (Keogh and Henry 2016; Long et al. 2016; Wolfert et al. 2017). Two different scenarios appear to play out within agriculture value chains: (1) closed, proprietary systems in which the producer is part of a highly integrated food supply chain and (2) open, collaborative flexible systems (Wolfert et al. 2017). These scenarios are influenced by the architecture and infrastructure of big data solutions and the control of data. If these scenarios are valid in mining, then mining companies will need to change the way they work with their supply chain and technology providers. Regardless of whether they build deep, long-term networks that are closed to competition or flexible, open, collaborative platforms, new business capabilities will be required that will challenge the current transactional lowest cost, lowest risk procurement models.

\subsubsection{Lessons from Digital Technology in Aerospace: New Management Capabilities and Network Governance}

Complex product systems (CoPS) are customized, one off or small batch capital goods which have large physical size, high investment costs, long life cycles, and engineering complexity with interconnected subsystems (Hobday 1998) such as power stations, airports, hospitals, and flight simulators (Acha et al. 2004). Mining operations involve many forms of CoPS such as processing plants, railways, and ports. Arguably a mine is also a complex product system being a one-off design with high complexity and interconnected subsystems, so comparisons with other CoPS industries are useful to understand the future of mining. Increasingly software and embedded intelligence are being integrated into CoPS industries, which allows comparisons to be made with the digitization of mining.

The aerospace industry can be classified as a CoPS with large multiorganizational, multinational projects to create and build aerospace vehicles. In this section two contrasting cases of innovation in the aerospace industry and parallels with the mining industry will be considered. Boeing's Dreamliner was an innovative project, particularly in terms of aviation technology with new avionics and computing systems that had never been used on large commercial aircraft. It also was innovative in the coordination of its design and production by globally outsourcing a significant proportion of design, engineering, manufacturing, and production along with new riskrevenue arrangements with these suppliers. However, the project suffered 
significant delays and an overrun in development cost of $100 \%$. This is not uncommon for larger CoPS projects, including mining projects (Merrow 2011; Flyvbjerg, 2015).

In an analysis of the project, Shenhar (2016) concluded that Boeing underestimated the level of complexity of the interdependencies between the technological innovations and the supplier network. Boeing treated the project as having a low level of dynamics and socio-political complexity, as if things are quite stable and the international cultural environment is mostly homogeneous. Given the globally distributed nature of the project, this was far from the case; however, there is no generally accepted best practice for managing such projects. Traditional project and program management tools rarely deal with change and managing innovation within a project (Davies et al. 2015; Steen et al. 2017). As Boeing found, managing a transition to a new way of organizing production requiring different technologies and supply chains with a high level of international sub-system integration requires new management capabilities.

Airbus has been a successful player in the aerospace industry with a track record of innovation in a CoPS environment. Key to Airbus' success was the development of a supply-chain organization model to maintain technical innovation (Kechidi 2013). Airbus evolved from an aircraft manufacturer to a technology system integrator. The stability of key partners in terms of the organizational model, while evolving and changing, resulted in a strong relationship where the suppliers evolved with Airbus. Although widespread, these partners were predominately located within Europe.

Airbus introduced technological innovation with each new aircraft which also shaped Airbus' organizational model. The modularization of technology at Airbus was based on subsystem components governed by subsystem integrator firms. This allowed Airbus to focus on managing the system and interacting with a smaller number of external firms. Generally, the mining industry has a very transactional and cost driven approach to its suppliers. As with Airbus, a mining company's governing role in the innovation ecosystem can shape the evolution of new technologies with suppliers. Developing strong stable relationships through a coordinated network with suppliers can accelerate and reduce risk in the innovation process in a CoPS environment.

Over the past 2 years, Airbus has undergone a more aggressive transformation as it sees enhanced competition and a risk of being disrupted and so is adopting American style management and business practices. This transformation includes trying different approaches to innovation in technology and product development, a focus on sensors, digital design, and digital manufacturing. The jury is out on whether Airbus will make a successful transition to this new hyper-digital environment (Gelaine 2017).

Looking at these two cases from industries that are more advanced in the adoption of digital technology yet similar to mining, we can see the important implications for the future of established mining companies: 
1. Digital technology can generate significant productivity gains but only if the technology enhances the coordination of production across the value chain and supply chain. Applying digital technology to specific points in the value chain will have limited impact.

2. Digitization and coordination of an integrated supply network requires new business and management capabilities.

3. The accumulation of data and experience will take time. Digitizing a mining operation and creating a new industrial ecosystem around digital technology is a long-term project.

4. Miners have an important role to play in shaping the new digital ecosystem. Rather than being passive buyers of technology and services, they need to become system integrators to capture the value of innovation across the industrial network and consolidate their competitive position by leveraging the intellectual power of this network.

However, these changes are also potentially disruptive for the incumbent dominant businesses because they have the potential to change the nature of competitive advantage and tip bargaining power in favor of businesses that supply technology to the miners. In the next section, we consider how technological changes within the industry can transform the dynamics of competition.

\subsection{The Digitization of Architectural Knowledge and the Impending Competition for its Control}

An outcome of digitization is the growing competition for control of architectural knowledge within the mining innovation ecosystem. The architectural knowledge we have in mind is that which enables the skillful coordination of different components of the mining system (e.g., development, production, processing, and distribution) in an attempt to maintain an optimal system state. Traditionally, this knowledge was embedded in the people, systems, and tools controlled by mining companies or, more recently, IT service companies. However, as the mining process becomes increasingly digitized and automated, traditional boundaries and roles are coming under pressure.

Digitization is happening at the level of the components and the systems linking these components together. At the component level, the functionality of mobile, heavy mining equipment has become critically dependent on software. Autonomous trucks, such as those developed by Komatsu and Caterpillar, provide insight into how knowledge boundaries are shifting at the component level. Traditionally, these firms would sell a mining company 
an asset. The mining company would then have its engineers and operators work to customize, tinker, hack, and otherwise innovate their way to improving the asset's performance in use. In terms of engineering, this mainly required mechanical and electrical systems. However, as digital control systems become central to asset performance, knowledge of software is obviously required to continue improving performance.

What is less well understood is that the access to and jurisdiction over this knowledge is problematic for mining companies because the software in question is usually provided, maintained, and protected by the original equipment manufacturers (OEMs). For example, OEMs can use obfuscation techniques to prevent miners from digitally upgrading or customizing the control system's source code, and thus restrict their ability to improve or adapt the asset's performance. Even if mining companies could access this code, OEMs claiming proprietary information can place licensing conditions on purchasers that limit who can access and edit this code. We are not aware of controversy around this yet in the mining industry, but the "Right to Repair" debate in the United States provides an illustration of how restrictive such licensing agreements can be. For example, John Deere locks farmers into license agreements that forbid them from attempting to repair their own tractors by requiring that they channel repairs through manufacturers and authorized dealers (Solon 2017). Digitization makes it possible to quarantine islands of knowledge at the component-level within the mining system and shift control of these islands to OEMs.

At the same time as digital islands are being walled off from mining companies, an influx of new entrants into the mining industry are seeking to build, codify, and control architectural knowledge at the level of the mining system. The abundance of digital data being produced within the mining system creates opportunities for firms such as IBM. These firms can draw on proprietary techniques to integrate, analyze, simulate, and predict mine production at the system level. It was with precisely this goal in mind that GE and South32 (2017) formed a 3-year strategic partnership in April 2017 in an attempt to leverage these techniques to drive performance improvements through better mine integration. These initiatives are likely to focus on both the codification of existing architectural knowledge and its augmentation through new processes. In doing so, firms such as GE and IBM are taking an important step towards gaining access to the architectural knowledge required to run a mine site. It remains to be seen how much of this knowledge they will end up controlling. However, similar to what we see playing out at the component level, a knowledge-based shift in the boundaries of the industry is currently underway.

These changes leave mining companies vulnerably placed with the eventual ownership of mining's architectural knowledge, and the margins that goes with it, in flux. It also asks interesting question regarding the nature of intellectual property and how it is secured. In the digital era, when mining systems and their components are so dependent on software programs 
for their competitive advantage, who will own the proprietary systems for running them? And in an era awash with industrial espionage, how will these highly codified digital programs be protected from competitors? The mining company of the future may look very different from what it is now, and the term company may be replaced with alliance network where one integrated digital platform competes with others in a similar way that Android competes with iOS. One interviewee, a North American R\&D director, was already considering the disruption of the large integrated mining company:

If we imagine a world in which a lot of the functionality of a mining system is delivered as a service instead of a product, then you'd be in a very different investment game with mining. It wouldn't be a major sort of CAPEX driven operation, it would be an operational excellence driven operation, and that would change a lot of things. First of all it would probably make it unnecessary to have large mining companies, which may be one of the difficulties in persuading them to do it. (North American R\&D director)

\subsection{Conclusion}

The mining industry currently has an idiosyncratic innovation ecosystem. It largely relies on importing innovation from suppliers and much of this innovation is embedded in improved processes so the innovation is frequently overlooked. However, mining will need to become more innovative to meet the inexorable challenges of rising costs, lower grade reserves in more difficult locations, and increased environmental and social scrutiny. Business as usual will not be an option.

Although the current short-term focus on the prospects for digital technology in mining revolves around cost reduction, we see a much broader impact of digital technologies as enablers of innovation such as simulation, modeling, real-time decision-making, and collaborative problem solving. Advanced automation will promote systemic solutions and improved efficiency across mine-to-mill, including critical areas such as water and energy use, which have traditionally been impeded by cross-department integration challenges.

Digital integration also will bring in suppliers as closer partners in mine performance as they use proprietary data collection and analysis methods to reveal ways to improve mining operations. As the challenges from energy costs, water, remote locations, and social license to operate escalate, mining companies will need to reinvent themselves to remain viable. This will mean a fundamental transformation away from large integrated mining companies 
to more agile networks of companies based on technology platforms and data for competitive advantage.

However, this increasing reliance upon supply chain companies to manage data will shift the balance of competitive power towards powerful tech companies like GE, IBM, and SAP. When Anglo American CEO, Mark Cutifani, foreshadowed at the 2013 World Mining Congress that innovative companies like GE might take over the mining industry, his words may prove to be prophetic rather than provocative.

\section{References}

Acha, V., Davies, A., Hobday, M., and Salter, A. 2004. Exploring the capital goods economy: Complex product systems in the UK. Industrial and Corporate Change 14(3):505-529.

Caldwell, N., Roehrich, J., and Davies, A. 2009. Procuring complex performance in construction: London Heathrow Terminal 5 and a Private Finance Initiative hospital. Journal of Purchasing and Supply Chain Management 15(3):178-186.

Castle, M.H., Lubben, B.D., Bradley, D., and Luck, J.D. 2016. Factors influencing the adoption of precision agriculture technologies by Nebraska producers, Presentations, Working Papers, and Gray Literature. Agricultural Economics Paper 49. http://digitalcommons.unl.edu/ageconworkpap/49

Davies, A., Macaulay, S., DeBarro, T., and Thurston, M. 2015. Making innovation happen in a megaproject: London's crossrail suburban railway system. Project Management Journal 45(6):25-37.Dodgson, M., Gann, D., and Salter, A. 2006. The role of technology in the shift towards open innovation: The case of Proctor \& Gamble. RED Management 36(3):333-346.

Dodgson, M., Gann, D., and Salter, A. 2007. In case of fire, please use the elevator: Simulation technology and organization in fire engineering. Organization Science 18(5):849-864.

Dodgson, M., and Steen, J. 2008. New innovation models and Australia's old economy. In Creating Wealth from Knowledge: Meeting the Innovation Challenge, J. Besant and T. Venables (Eds.), 105-124. Cheltenham, UK: Edward Elgar.

Edraki, M., Baumgartl, T., Manlapig, E., Bradshaw, D., Franks, D.M., and Moran, C.J. 2014. Designing mine tailings for better environmental, social and economic outcomes: A review of alternative approaches. Journal of Cleaner Production 84:411-420.

Eslake, S., and Walsh, M. 2011. Australia's Productivity Challenge. Melbourne, Australia: Grattan Institute.

Flyvbjerg, B. 2015. What you should know about megaprojects and why. An overview. Project Management Journal 45(2):6-19.

Francis, E. 2015. The Australian Mining Industry: More Than Just Shovels and Being the Lucky Country. Canberra, Australia: IP Australia.

Gann, D., and Dodgson, M. 2008. Innovate with vision. Ingenia 36:45-59.

GEandSouth32.2017.South32andGEenterdigitaltransformationstrategicpartnership. https://www.south32.net/docs/default-source/media-releases/south32-andge-enter-digital-transformation-strategic-partnership.pdf?sfvrsn=2bd6a0af_7. 
Gelaine A. 2017. A critical look at Airbus's push for disruption: In its bid for selfdisruption, is Airbus going too far? Aviation Week \& Space Technology, December 6, 2017, 1-3.

Global Mining Standards Group (GSMG) 2017. Building a strategic vision of future mining: March 2017 corporate member report, Global Mining Standards and Guidelines Group. www.globalminingstandards.org.

Hanson, D., Steen, J., and Liesch, P. 1997. Reluctance to innovate: A case study of the titanium dioxide industry. Prometheus 15(3):345-356.

Hayward, M., Caldwell, A., Steen, J. Liesch, P., and Gow, D. 2017. Entrepreneurs capital budgeting orientations and innovation outputs: Evidence from Australian biotechnology firms. Long Range Planning 50(2):121-133.Henderson, R., and Clark, K. 1990. Architectural innovation: The reconfiguration of existing product technologies and the failure of established firms. Administrative Science Quarterly 35:9-30.

Hobday, M. 1998. Product complexity, innovation and industrial organization. Research Policy 26:689-710

Hodge, R.A. 2014. Mining company performance and community conflict: Moving beyond a seeming paradox. Journal of Cleaner Production 84:27-33.

Kastelle, T., and Steen, J. 2011. Ideas are not innovations. Prometheus 29(1):39-50.

Kemp, D., and Owen, J.R., 2013. Community relations and mining: Core to business but not "core business." Resources Policy 38:523-531.

Keogh, M., and Henry, M. 2016. The implications of digital agriculture and big data for Australian agriculture, research report. Sydney, Australia: Australian Farm Institute.

AQ 7 Kunz, N.C. 2013. Sustainable water management by coupling human and engineered systems. Centre Water Minerals Industry, Sustainable Minerals Institute, The University of Queensland, St Lucia.

Kunz, N. C. 2016. Catchment-based water management in the mining industry: Challenges and solutions. The Extractive Industries and Society 3(4):972-977.

Kunz, N.C., Kastelle, T., and Moran, C.J. 2017. Social network analysis reveals that communication gaps may prevent effective water management in the mining sector. Journal of Cleaner Production 14:915-922.

Marra M., Pannell, D. J., and Ghadim, A.A. 2003. The economics of risk, uncertainty and learning in the adoption of new agricultural technologies: where are we on the learning curve? Agricultural Systems 75:215-234.

McKee, D., 2016. Understanding Mine to Mill. Canberra: The Cooperative Research Centre for Optimising Resource Extraction (CRC ORE).

Merrow, E.W. 2011. Industrial Megaprojects: Concepts, Strategies and Practices for Success. New York: John Wiley and Sons.

Mintzberg, H. 1981. Organization design: Fashion or fit? Harvard Business Review 59:103-116.

Mitchell, P., Bradbrook, M., Higgins, L., Steen, J., Henderson, C., Kastelle, T., Moran, C.J., Macaulay, S., and Kunz, N.C. 2014. Productivity in Mining: Now comes the hard part, a global survey. Sydney, Australia: Ernst and Young.

Mitchell, P., and Steen, J. 2014. Productivity in mining: A case for broad transformation. Sydney, Australia: Ernst and Young.

Mitchell. P., Steen, J., Sartorio, A., Bolton, W., MacAaulay, S., Higgins, L., Kunz, N.C., Yameogo, T., Hoogedeure, W., and Jackson, J. 2017. How do you prepare for tomorrow's mine today? Sydney, Australia: Ernst and Young. 
Nadolski, S., Klein, B., Elmo, D., and Scoble, M. 2015. Cave-to-mill: A mine-to-mill approach for block cave mines. Mining Technology 124:47-55.

Pierce, F.J., and Nowak, P. 1999. Aspects of precision agriculture. Advances in Agronomy 67:1-86.

Pierpaoli, E., Carli, G., Pignatti, E., and Canavan, M. 2013. Drivers of precision agriculture technologies adoption: A literature review. Procedia Technology 8:61-69.

Salter, A., Gann, G., and Dodgson, M. 2005. Think, Play, Do. Oxford, UK: Oxford University Press.

Samuelson, P. 2016. Freedom to tinker. Theoretical Inquiries in Law 17(2):562-600.

Schimmelpfenning D., and Ebel R. 2016. Sequential adoption and cost savings from precision agriculture. Journal of Agricultural and Resource Economics 41:97-115.

Schumpeter, J. 1912. The Theory of Economic Development. New Brunswick, NJ: Transaction Publishers. (Tenth printing, 2004.)

Shook, A. 2015. Innovation in mining-Are we different? AusIMM Bulletin, April. https://www.ausimmbulletin.com/feature/innovation-in-mining/.

Solon, O. 2017. A right to repair: Why Nebraska farmers are taking on John Deere and Apple. London: The Guardian. https://www.theguardian.com/environment/2017/ mar/06/nebraska-farmers-right-to-repair-john-deere-apple.

Sonka, S.T. 2016. Big data: Fueling the next evolution of agricultural innovation. Journal of Innovation Management 4(1):114-136.

Syed, A., Graftan, Q., and Kalirajan, K. 2013. Productivity in the Australian Mining Sector. Canberra, Australia: BREE.

Tilton, J., and Landsberg, H. 1997. Innovation, productivity growth and the survival of the US copper industry. Washington, DC: Resources for the Future Discussion paper, pp. 97-41.

Watcharaanantapong, P., Roberts, R. K., Lambert, D. M., Larson, J. A., Velandia, M., English B. C., Rejesus, R. M., and Wang, C. 2014. Timing of precision agriculture technology adoption in US cotton production. Precision Agriculture 15:427-446. 


\section{Author Query Sheet}

Chapter No.: 1

\begin{tabular}{|c|c|c|}
\hline Query No. & Queries & Response \\
\hline AQ 1 & $\begin{array}{l}\text { Please check whether the shortened running } \\
\text { head is ok. }\end{array}$ & \\
\hline AQ 2 & $\begin{array}{l}\text { Please check and confirm in the sentence } \\
\text { "A third feature..." about the "third feature" } \\
\text { here. Where is the first and second feature if } \\
\text { you are listing in order? }\end{array}$ & \\
\hline AQ 3 & $\begin{array}{l}\text { In the following sentence "This last point...." } \\
\text { Last point is discussed. Please check and } \\
\text { confirm where the previous points if you are } \\
\text { going to specify last point here? }\end{array}$ & \\
\hline $\mathrm{AQ} 4$ & $\begin{array}{l}\text { Please provide the details for "Scott-Kemmis } \\
(2013) \text { " in the reference list and source line for } \\
\text { Figure 1.2. }\end{array}$ & \\
\hline AQ 5 & $\begin{array}{l}\text { "Please provide the details for "Cohen } \\
\text { and Levinthal (1990)," "Steen et al. (2017)," } \\
\text { "Dodgson et al. (2005)," "Saefong (2016)," } \\
\text { "Forsythe et al. (2015)," “Wolfert et al. (2017)," } \\
\text { "Wolfert (2017)," “Long et al. (2016)," “Shenhar } \\
\text { (2016)," “Kechidi (2013)" in the reference list. }\end{array}$ & \\
\hline AQ 6 & $\begin{array}{l}\text { Please check and provide the "interviewee" } \\
\text { who is left out in the quoted text "This effort } \\
\text { will..." }\end{array}$ & \\
\hline AQ 7 & $\begin{array}{l}\text { Please provide the publisher location for "Kunz } \\
\text { (2013)," "McKee (2016)" in the reference list. }\end{array}$ & \\
\hline AQ 8 & $\begin{array}{l}\text { Please cite "Samuelson (2016)," “Global Mining } \\
\text { Standards Group (GSMG) (2017)" in the reference } \\
\text { list. }\end{array}$ & \\
\hline
\end{tabular}

